\title{
The Role of the Press in the Unilateral Disengagement Plan of Israel from Gaza Strip
}

\author{
Yaron Katz \\ School of Communications, Bar-Ilan University, Ramat-Gan, Israel \\ Email: yaron@ykatz.com
}

Received October $27^{\text {th }}, 2011$; revised February $9^{\text {th }}, 2012$; accepted March $6^{\text {th }}, 2012$

\begin{abstract}
The Disengagement Plan is the name assigned to the plan enacted in the summer of 2005 to evict all Israelis and military bases from Gaza Strip and four isolated settlements in northern Samaria and to withdraw unilaterally. The plan was controversial, yet it won the support of the majority of the cabinet and the Knesset members, as well as the support in Israel and the world. The eviction process of the residents was accompanied by vast activities of the army and police forces in fear of violent acts by the evacuees, and by extensive media coverage. It was one of the longest and most covered events in the history of Israel and intensified the conflict between security needs and free press. In democracies such as Israel, which faces security needs on permanent basis, the media are expected to carry social responsibility duties of not publishing information that is sensitive to national security. It is commonly agreed that although Israel is a democratic state where freedom of speech and freedom of the press are cornerstones of its existence, in all that relates to security things should be different, and security issues are above the need of the media to publish and the need of the public to know. The position of the press in the disengagement and the way they dealt with this dilemma are analyzed in this study based on covering reports in the main Israeli daily newspaper-Yediot Achronot-during the period from January 1, 2005 through August 24, 2005, when the evacuation of all Israelis from Gaza Strip was completed.
\end{abstract}

Keywords: Press; Coverage; Israel; Conflict; Security

\section{Introduction}

Essential aspects of democracy are freedom of information and freedom of the press. In addition to the provision of essential information to the public, these basic principles are vital to social and political developments in democratic societies. The free flow of information allows public debate and political participation and enhances the influence of public opinion. The free flow of information, with the advent of new technology, opens up new opportunities to spread democracy and values of free speech.

But there is a fundamental conflict between the principles of open coverage dominated by global media services having no local obligations, and security needs handled by security agencies and intelligence services that need to rely on secrecy by preventing the publication of their activities. This conflict has identified the Israeli society for many years, and has been intensified since the globalization of media coverage.

The Israeli-Palestinian conflict has been an ongoing dispute since the establishment of the State of Israel and shows no definite endpoint. Its magnitude changes according to periods of war and violence and periods of truce and temporary intervals of violence, but its impact is central and constantly reflected in the life of the Israeli society. The political purpose of the Disengagement Plan was to make a clear separation between Israel and Gaza Strip, based on the understanding that no peace agreement or any form of mutual agreement can be reached. This assumption was made even clearer, when in May 2005, three months before the disengagement, as the terrorist organization of Hamas won the parliamentary election in Gaza Strip.
Subsequent to IDF pullout, armed Hamas forces took control of the authority and formed a government. Hamas calls for the destruction of the state of Israel.

The political events demonstrate political conflict that identifies Israel. According to the position of the past prime ministers, Yitzchak Rabin and Ehud Barak, the Israeli-Palestinian conflict is a continuing dispute with no ending point, during which there are periods of calm. The Israeli goal according to this opinion is to assure that the calm periods would last as long as possible. This statement was made publically by Barak, who led, as the Israel Defense Minister, the military operation in Gaza Strip in December 2008-January 2009 (Operation Cast Lead). This operation waged as a reaction to rockets fire into Israel in spite of the disengagement. And indeed, it was only four years after that another military operation by Israel took place in Gaza Strip, in November 2012, again after rockets fire into Israel (Operation Pillar of Defense). In both operations, the Israeli army did not enter the refugee camps in Gaza and launched a limited operation that lasted until a cease fire was reached following pressure by global political forces, mainly the United States and Egypt.

Indeed, the conflict is impacted by the involvement of political and global factors and gains a widespread and constant coverage by the international media, especially in times of military conflicts or peace initiatives. The role of global forces is evident in the impact of new media services on Israeli society (Gilboa \& Katz, 2001; Katz, 1999). It is evident though that Operation Cast Lead lasted three weeks as the Bush Administration did not pressure Israel to a cease fire, while Operation Pillar of Defense lasted only one week as the Obama Administration put a lot pressure on Israel, including a mission of the 
Secretary of State, Hilary Clinton, to the region. Another notable aspect of the two military operations is that both took place after the elections in the United States and ended before the new administration took office.

Nevertheless, the unilateral disengagement by Israel from Gaza Strip is different from other events taking place in the Middle East in being an unliterary act carried out by Israel, as part of an organized and conceived plan of the government. Different from other peace initiatives or military operations, this was a well-planned operation that was executed after months of preparations involving government, military and media sources, and was widely supported by the global community.

Gaza strip area was until 1948 part of the western Negev in Israel. The expression "Gaza Strip" struck roots when the border between Israel and Egypt was erected following the cease fire agreements in 1949. It is a narrow strip of land between Israel and Egypt, 5 to 7 kilometers wide and reaches 12 kilometers in the southern part, and 45 kilometers long, with a total area of 360 square kilometers. The area was occupied by Israel in the six day war, in June 1967. The strip is considered the most crowded area in the world, with more than three million residents, half of each live in Gaza City and the rest in crowded refugee camps. The vast majority of the strip's population is Sunni Muslim (3).

Following Israeli occupation of the area, Israeli settlements were built on the strip. Katif bloc (Gush Katif) was founded at the beginning of the eighties by a group of representatives of communities from Yesha movement (a movement of settlements in Yehuda, Shomron and Azza-Judea, Samaria and Gaza-the land occupied by Israel in 1967) and Yamit evacuees (which was returned by Israel to Egypt after the peace agreement). 7500 people lived in the jurisdiction of the regional council of Gaza coast in 22 settlements. 6000 residents lived in north Samaria in four isolated communities.

The goal of this study is to examine the role of press coverage in major political and military campaigns in the MiddleEast and the Israeli-Palestinian conflict. According to Maoz (2006), the news media are a major source of public information on political processes and can be regarded as a crucial tool for mobilizing opinions in political and social conflicts and disputes. In the Israeli-Palestinian conflict, news-reported information concerning the opponents' response to a compromise proposal in conflict can influence attitudes and assessments of the parties concerned. Tenenboim-Weinblatt (2008) found that the mainstream press-in tune with political elites and public opinion-largely supported the political and military goals. When the disengagement had finally begun-after months of preparation and fiery debates - the Israeli press was in a highly ambivalent position with respect to the trauma discourse. Beckerman (2005) found that the position of the media and their unequivocal support for the plan had an important role in the success of the IDF media campaign, as they prepared the public for it and helped to insure the steady 60 percent of support it garnered.

The study examines the media coverage of the main daily newspaper in Israel, Yediot Achronot, from the beginning of 2005 until the disengagement implementation, at the end of $\mathrm{Au}-$ gust 2005. The paper discusses the dilemma of the press in the disengagment plan, as the media are expected to carry social responsibility duties of not publishing information that is sensitive to national security. In contrast, changes in approach regarding the need of the media to publish and the need of the public to be part of the political debate have created a new social structure that maintains and deploys the conflict between national security and media coverage.

\section{The "Security Culture"}

The impact of media coverage on the issue of national security has always been one of the cornerstones of Israel's very existence. Israel has traditionally granted freedom of expression to the media in every area but state security, and was unique in the world in the need to balance national security issues against the imposition of the media. The need to reconcile both free press and national security is a topic that has long occupied Israeli society. Debate has focused on the imperative of providing full coverage of events even during wartimes or other security threats while not harming state security. The main dilemmas have been whether or not to publicize events that might elicit violence or weaken morale; the way of maintaining credibility despite security needs and censorship limitations; and how to properly balance between the public's right to know and the restrictions of censorship (for instance: Eisenberg, Caplan, Sokoloff, \& Abu-Nomer, 2003; Goldscherder, 2002; Kimberling, 2003; Levi-Paur, Sheffer, \& Vogal, 1999; Shafir \& Peled, 2002).

In examining social changes and political dilemmas in Israel, it is evident that the army is an integral part of the life in Israel (for example: Caspit, 2002; Shavit, 2002). This process is unique to Israel, as national security and freedom of the press are two grand domains of its society: it is considered as a state with free press and at the same time it is still in a state of war. This unique situation requires limitations on publication of information that relates to national security affairs; however this concept is being threatened by global media coverage of Israel's and Middle East affairs (Hezog, 2004).

The principle of free communications differentiates Israel from the countries surrounding her. The media are considered to be non dependent on the government and enjoy wide freedom of expression in every field except that of security. The security situation that has besieged Israel for many years, following wars and terrorist activities, caused the imposing of bans on media coverage in matters connected to the security of the state. The "security culture" that characterizes the Israeli society was formed since the security subject is perceived as one of central placing in the national conscience and has central ramifications in all areas of life. Israel can be referred to as a conscript society in which not only the army but the public in general is ready for enlistment for the sake of what the government defines as a national interest.

The "security culture" has many social ramifications, as the need to bridge between free communications and national security is a subject that continuously and intensely engages the Israeli society. Its impact is expressed in the need to supply up-to-date information at the time of war or during military activities while maintaining the utmost value of security. Since dealing with the dilemma of reporting events that could cause violence or hurt national moral, it is necessary to present a reliable reality while allowing expression of a wide variety of existing opinions and a balance between the right of the public to know and censorship limitations (Melman, 1993).

Another aspect the dilemma is that the strategy of Israel Defense Forces (IDF) is defensive while its operations and tactics are offensive and cut to the heart of national identity. The dis- 
tinction between defensive values and offensive operations can provide the means to understand the unique role of the IDF in Israeli heritage and society, and the sever impact on the Israeli society when such distinction is broken (Sucharov, 2005).

Global and local trends that influenced the change of coverage policy on security matters caused a change in the role of the media in society: while in the past, the army had sole authority to ban advertisement of information in different fields, today local media bear most of the weight of preserving a balance between the right of the public to know and the protection of state security, and their role is to balance between local and global trends in coverage of security matters.

Today security issues are being discussed by local media with almost no limitations, including detailed descriptions of military operations and personal stories of soldiers, public discussion on security issues and peace negotiation, including criticism of government actions and plans, debates on security needs, publication of official reports and exposure of past events with the inclusion of sensitive information on army operations-some of them subject to criticism and intense public debates. Once initial information had gotten out, because Israeli authorities cannot control foreign media, it is virtually impossible to prohibit publication of additional information. Foreign media reports serve as a catalyst in this process, since globalization and technology are not obliged to the limitations imposed by the military authorities. These include global media services, advanced technology that allows global and unlimited coverage, such as cellular and satellite telephones, portable computers, and ready-available satellite links, and global services providing unlimited information (such as the Internet).

The communications revolution created a social change following the exposure to global media coverage that is also available to Israelis. The advent of new media has changed local media policy regarding state security and the perception of the public of the role of the media in publishing information that was once considered classified. If in the past it was possible to prevent exposure of information for security reasons, todaygiven the existence of global means that do not consider local rules and are not under the authority of the Israeli government - the new reality obligates a compromise between global influences and local needs. As a result there is a change in the social attitude to subjects that in the past were defined as being security sensitive and whose advertisement could hurt state security.

The concept of national security, which Israel is identified with since its establishment, has been under siege with the growing impact of global television transmissions, which can be picked up in Israel also. Following the availability of classified information in terms of national security, the legitimacy of all governments, and Israel's in particular, to regulate broadcasting became questionable. New technological means, such as satellites and the Internet- together with traditional means of information delivery that are readily-available around the world, such as newspapers, magazines, and radio stations (some of them can be received via satellite) — have forced policy changes in regards to national security affairs.

Israel has been pushed to control its press for reasons of national security ever since its independence, as the need to limit freedom of the press for reasons of national security has been a matter of national consensus. This is now changing, mainly through the impact of global media coverage, and the commitment to protect freedom of the press in Israel has become al- most equally strong. This can be explained in that the main role of the media is in the impact of public opinion, while extensive news coverage changes the way governments operate in wartimes. Although public opinion and media organizations generally agree that during wartimes censorship becomes acceptable, they do not distinct Israel as being in a constant state of war. There is a fundamental difference in the way global media see security matters in wartimes and during other times, even if different sorts of military activities are still in progress (for example: Avraham, 2003; Horowitz, 1985; Peri, 1999; Lissak, 1992; Pedatzur, 1998).

The "security culture" that stands for preventing exposure of security information was badly shaken following the inability to control information coming in through different media sources. The dillema of free coverage and security needs had been intensified during the evacuation process. The media had a big role, as the continuous coverage of the position of the government and the army coupled with openness to the painful process was an influential factor on a non violent evacuation. The position of the press of preferring to show the emotional hardship of the evacuation rather than engaging in hopeless battle against the military forces constituted a significant and major factor in the impressive success of the military operation and total realization of the goals of the Israeli cabinet's resolution to evacuate the Israeli settlements from Gaza Strip.

\section{The Press Position}

The research examines the reports publicized in the main daily newspaper of Israel-Yediot Achronot-from August 1, 2005 through August 24, 2005, with the completion of the evacuation of Israeli citizens. At the beginning of the coverage, the paper focused on the relationship between the army and the residents and expressed the army's position on the fear from the residents' violence. Reports appeared daily in the paper's main headlines creating potential scenarios during the evacuation. On January 4, 2005 the headline warned of soldiers' refusals to take part in the evacuation and even mentioned the possibility of massive refusal. An article was printed the next day under the headline "stuck in the mud-an army's senior: it is as hard with the settlers as with the Palestinians", which depicted the IDF in a favorable light and the settlers as jeopardizing a historic process. The articles printed on the following days alerted from potential scenarios: "The horror script"-a front line article warning from bloodshed and "the Refusenik Brigade"about reserve officers who had signed a letter stating that they would object to being drafted to implement the disengagement. Later on, favorable articles about Sharon and the army's position were published: "the Prime minister defends the soldiers", and "Sharon met yesterday with the soldiers, policemen and the border guards". On the next days, the army's actions against the refusal appeared: "the refusal's storm - the punishment: expulsion from the army", "the wife of the head of the Manpower branch: I live in fear for my son"- the words of a senior officer's wife, portraying the settlers in a negative light, "The discharge" - on discharging reserve officers, "disengagement at any cost," on taking stricter steps against settlers who would thwart the evacuation, "fellow sufferers"- the story of two brothers who found themselves on the other side of the conflict: a settler from Netzarim against his brother, an officer, one of the commanders of the evacuating forces.

During the month of February 2005, the articles relayed the 
conflict between the settlers and the state while magnifying the foreseeable conflict, emphasizing the potential risks and the political implications of the historical process: "the demonstration of the 150 thousands", an article about a show of force by those opposing the disengagement in front of the Knesset, "the goal: refusal in the General Security Forces”, about the settlers attempts to convince policemen to refuse orders of evacuation, and "the settlers: we will hunger strike" - a report about settlers' leaders threatening to take measures of desperation to shock the country. Other articles presented the dilemmas of the settlers of fighting the army: "outside they demonstrate, inside negotiate"-about the deliberations on the monetary compensations for the evacuees, and "signed the evacuation", on 38 families from two settlements in the northern part of Gush Katif (Eli Sinai and Nissanit), who signed an agreement to move to a community next to the nearby city of Ashkelon. This article presented the signing as a victory of the disengagement authority in the battle against the settlers, but the following articles continued to feature stories on those opposed the evacuation and the risks that the security forces face: "the incitement is running wild-hate letters"-about threatening letters sent to ministers, "preparing for hundreds of detainees every day"about the fear from war of attrition by the opponents to the evacuation to break out before the disengagement implementation, "the settlers: we will fight even at the cost of our lives", "3000 weapons are in the hands of the settlers", "the horror script" - about a secret document found in the police according to which most of the settlers will violently resist the evacuation, and "the head of the National Security Forces warns from the extreme right wing: dozens are ready to murder Sharon".

The paper covered the political resolutions favorably, even when the process showed difficulties. The report on the chief of staff resignation was presented as a matter of fact and briefly, and already on the following day the paper continued to report on the progress of the political process of passing the Evacuation-Compensation law: "leave Gaza and get two million shekels", and "the Knesset approved the evacuation of the settlements". The paper referred also to the emotional side of the evacuation's decision on the Prime Minister Sharon, the man who had built the now dismantled settlements. The reports' headlines relayed Sharon's feelings: "the hardest decision of my life," and "tears in the eyes". Also the reference to the new Chief of Staff was positive: "Chief of Staff Halutz: the expectations from Halutz are sky-high" — an article depicting the first Chief of Staff appointed from the air force who must pass successfully the disengagement test, especially in light of the danger of violence, as described in other articles.

Following the approval of the disengagement in the Knesset, on February 2, the press coverage started to refer to the pullout as a done deal, hence the new forming reality was described: "the State of Israel is saying goodbye to Gaza", "in two months the first settlement is being evacuated from Gaza", "eviction orders are on the way", "a farewell to Gaza”, along with articles about the planned implementation of the disengagement process: 5000 policemen and tens of dozens of soldiers will participate in the operation encircling Gush Katif in six rings of security, a long convoy of policemen and soldiers will enter to evacuate the settlers, while the evacuating forces will be the most experienced and trained border guards and policemen in handling situations of disturbing the peace, and hundreds more policemen will go through training in handling the evacuation. The plan was presented as extensive and thorough planning to be carried out by the most experienced police and military manpower.

During March the paper focused on presenting the settlers' state of mind. Issues raised included deliberations on monetary compensation to the evacuees, coverage of the sensitive aspects of the process in a regular column recounting each time the story of one evacuated family (the column was titled "my home"), the position of those opposing the evacuation, and the government's position vis-à-vis the various camps among the residents of Gush Katif-those who are ready to cooperate and those who are planning to resist the evacuation.

The paper's headlines were extreme. On one hand they described the generous monetary compensation the evacuees would receive: "an offer to the evacuees: villa by the sea", "the caravillas (the caravans that were supposed to host the evacuated settlers temporarily) of the evacuees”, "2025 do-it-yourself housing units for the settlers in the southern communities", "5 star evacuation" - on the evacuation of the settlers to hotels as temporary housing after the pullout, and "give more money, get silence" - an article portraying the settlers as being greedy. On the other hand, the portrayal of the potential opposition pointed to violent evacuation intentions: "Gush Katif is hoarding for a siege", "hundreds of settlers have changed their addresses to Gush Katif. That is how those who opposed to disengagement are preparing for the evacuation day", "settlers are threatening: we will burn more roads", "settlers on the road"-a factual report on those opposed to the disengagement blocking main roads inside the country, and "a road commando"-a description of the actions of the anti-disengagement as a clandestine and underground organization.

The government position was reported as being unequivocal, in a script similar to that presented in January: first a sympathizing attitude toward the government vis-à-vis the violent settlers then, the army's plan to fight those resisting the evacuation, and finally the outcome: the government policy is a success. The sympathizing reports to the government presented the determination of the Prime minister: "Sharon disengaged from the last obstacle" - on the Knesset's rejection of the disengagement referendum, and "Sharon at all cost" —on the wide public support for Sharon after four years in service. The army's action was described in the plan to fight the opponents to the disengagement: "the opponents to the disengagement who would interrupt the traffic are expected to get lengthy imprisonment”, and "the marine commando will evacuate settlers through the sea”. The expected outcome of the struggle appeared in an article which presented the success of the government's policy: "Eitam proposes to collect weapons"- on the proposal made by an anti-disengagement cabinet member (Effi Eitam) to collect weapons from the settlers, explained as though the minister and evacuees had come to terms with the evacuation's reality.

Deliberations on the plans of post disengagement implementtation had commenced on April. The articles raised a wide range of issues, among them the question of what would happen to the homes, synagogues and cemeteries, as well as alternative housing units for the evacuees. The paper's headlines stressed the government position: "a plan: the homes will be given away, the synagogues demolished”, "Sharon: cemeteries will not be evacuated forcibly", "Sharon will oppose demolition of homes in Gush Katif”, "let's bring in the bulldozers”- on Sharon's words during a visit to Nitzanim dunes, the place where the new homes of settlers were built, "the entire Gush Katif will move to Nitzanim”, “move as one bloc”- on Sharon's words in 
a meeting with the evacuees, "farewell to the communities"on Sharon's decision to allow only for the residents of Gush Katif to conduct a farewell ceremony from the evacuated communities, and "settlers in Nitzanim" —an article about the negotiation between the Settlers and the government on relocating to Nitzanim. Other articles dealt with the army's assessments on the security state after the withdrawal: "the intifada will be renewed in the fall" - on the Palestinian reaction to the unilateral withdrawal, and on the other hand "disengagement is expected - disengagement phase 2"-an article about the government future plans for additional unilateral disengagement from Judea and Samaria in case there would not be a Palestinian partner, and two days later an article was publicized in response about "a storm erupted after the disclosure of the disengagement phase 2" to which Sharon had denied its existence. Towards the end of April positive news appeared on the issue: "Israel and the Palestinians opened discussions to coordinate the disengagement".

Throughout this period reports kept on alerting from violence during evacuation. Also, the front page headlines on this issue presented the army's position: "concern: a Jewish terrorist act to thwart the disengagement", "15 thousand security men will evacuate the settlers", "Sharon: It feels like on the eve of civil war", "military policemen will make sure that the evacuators would not loot the homes of the settlers", and "the big war game - the disengagement" - an article about an extensive army exercise where all possible scenarios that may occur during the evacuation had been tested-from settlers' passive resistance to barricading inside the homes threatening to commit suicide or to fight with live ammunition.

At that time the first critical article against Sharon was published: "we are on the way toward a big mess"-about the pullout ensuing problems: there are no alternative housing solutions for the evacuees, factories' owners are facing unemployment, there are no vocational solutions for others, no alternative for farmers' employment, schools are not ready to absorb students, and it is not clear where the cemeteries will be relocated. But the criticism stopped, instead the paper publishes articles about the commencement of the disengagement, when four months before the scheduled date for the pullout, the army had started to remove military equipment from the bases in Gaza Strip. At the same time, articles continued to warn against the perils of the evacuation: "concern: demonstrators will attack Gush Katif police”, "toward the disengagement: policemen will exert reasonable force against children”, “49\% of the settlers: during the evacuation we will obey the army not the rabbis. $39 \%$ will obey the rabbis". Towards the end of the month the articles begin to express possible solutions to the problems: "Big synagogues would be demolished", and "the state acquired land for the evacuees".

\section{Coverage of the Evacuation}

In the period that started on May 2005, three months before the disengagement operation, many articles about the government position favoring the disengagement against potential dangers from violence by those opposed to disengagement were published: "Sharon: the disengagement will assure a Jewish majority", "the Prime Minister will approach the Palestinians with a formal proposal", "Sharon: there is a solution to all evacuees", "the disengagement will be coordinated with the Palestinian", "Sharon: I will implement the disengagement even if all roads would be blocked', "the Prime Minister put pressure and the new caravillas were brought in to Nitzanim”, and "evacuation order"-on the army plans for evacuation day. On the other hand, articles about police investigation on suspicion of corruption by the Prime Minister were few, published only in response to discussions on the issue in the Knesset. Little focus was put on the political dispute in the cabinet on the disengagement, and the coverage emphasized the strong and unequivocal position of the Prime Minister to the opposition inside the government and the Knesset (the Israeli Parliament).

The media coverage seldom reported on the government's solutions for alternative housing for the settlers, although review of the events since the disengagement showed that the government position, as it was expressed in the media, failed to present the true reality, and many of the evacuees had still not received permanent alternative housing. Other than one report - "buds of failure"-a review conducted by Yediot Achronot showing that 65 days before the evacuation the government had not yet met the plans regarding the evacuees, the reports that dealt with the alternative housing issue expressed the unequivocal position of the government: "be quite and get Nitzanim" -on the government's position that those resisting the evacuation would not be able to move to the alternative housing location, "you have one week to decide", on the government announcement to the evacuees that they have to make a decision on their alternative housing, and "the majority in Gush Katif: let's move to Nitzanim".

A few reports dealt with the international implications of the process, and referred mainly to the US position: "the president of the US promised Sharon: in return for withdrawing from Gaza you will receive a special aid for developing the Negev and the Galilee", and "Israel will request from the US half a billion dollars for the disengagement”. Also, there was little coverage on predictions of what would happen after the withdrawal: "rockets will continue to be launched after the disengagement", "victory to Hamas in regional elections", and "Hamas is building an army".

The position of the press in analyzing the outcome of the disengagement needs to be examined in light of the events that actually happened since then. The rise of Hamas to power before the disengagement implementation and the ongoing rockets launching into Israel thereafter, including the need for two large military operations in Gaza Strip, had to be significant factors which the media should have brought up for public discussion before the implementation of the evacuation.

The paper chose to present the unequivocal position of the Prime Minister even on this issue, despite the claims for security risks in case the disengagement plan is implemented: "to stop the disengagement if Hamas will be elected"-the foreign minister announcement rejected by Sharon claiming that the disengagement is a unilateral process to be executed unrelated to the election of the Palestinian Authority, and "the Chief of staff: we will decide when to react"- - a response to a rocket fire killing three workers in Gush Katif.

Along with the sympathetic presentation of the government position, the violent actions of the settlers appeared unequivocally in the headlines: "a soldier was injured in a demonstration against the fence", "2 border guards squadrons will deal with the Jewish rioters", "soldiers begin training in breaking into settlers homes", "police officers came to talk with the settlers in Homesh and were warned", and in the sub headlines: "when the evacuating forces come we will connect ourselves to gas bal- 
loons". The plans of those opposed to disengagement were inserted in big headlines: "the new weapon, a law suit against each officer", "roads blockers, the new system”, "attrition war", "we won the police"- on blocking main intersections around Israel as a protest against the disengagement, "that's how we will paralyze the disengagement"-on the disengagement opponents' plan to jeopardize the army's plans, "two months before the evacuation: 20 new families in Sa-Nur settlement", "settlers are threatening the life of a policeman", "suspicion: those opposed to disengagement volunteering to the police force in order to thwart the disengagement”.

Other reports relayed the determined position of the army against those opposed to disengagement: "a soldier could shoot a settler who had opened fire- only with the approval of a senior officer", "disengagement under fire" —on the army's fear of violent evacuation, "during the evacuation: it is allowed to shoot also Palestinians demonstrators", "the disengagement will cause a rift inside the army" — on the fear of the army from the magnitude of the protest against the evacuation, "we will implement the disengagement with determination and sensitivity" - on the first speech of the new Chief of Staff, Dan Halutz, calling not to get the army involved in the political debate, clarifying: I will not accept refusal, "we first handle the shooters and then we will evacuate the settlers"- on the Chief of Staff announcement not to carry out evacuation under fire, "the disengagement will be implemented"-on the Chief of Staff announcement warning the settlers' leaders that they will bear responsibility for bloodshed".

Two months before the disengagement articles about the operation itself were published. The headlines were informative and started the countdown: "60 more days to disengagement", "only two months left", "from Sunday: the settlements in northern Samaria are to be dismantled", "settlers from Gush Katif signed the evacuation agreement", "today is the meeting between Sharon and Abu Mazen”, and "about 3000 foreign correspondents are expected to arrive”. The headlines presented the disengagement process as a national operation and quoted the Prime Minister words against the settlers: "rampage"-on road blocking by the right wing groups, "Sharon: law breakers - a threat to the state" - on the refusal in the army as a jeopardy to democracy, and "Sharon: this is a battle for the country"-following mass demonstrations of disengagement's opponents. The paper reflected also the public opinion against the demonstrations: "drivers against blockers", and reported the survey results showing public support in the process: "Yediot Achronot poll: 53\% for the disengagement, 38\% against".

On July, one month before the evacuation, the reports dealt with the different aspects of the conflict between the government and the evacuees: articles about the army preparations for summoning the withdrawal opponents to Gush Katif to protest the pullout, articles about the preparation by some residents for the evacuation, along with reports about the emotional confrontation of other settlers with the evacuation, such as the dilemmas of the bereaved families, and reports about negotiation on the compensation. Further reports described the potential resistance to the evacuation: "blockade alert"- on the thousands of people planning to arrive to Gaza Strip and stay there until the evacuation, "shuddering demonstration"-on wearing orange patches as a protest against the evacuation, "the settlers cut the fence and confronted the police force"-on confrontations between the disengagement opponents and the military forces, "concern: thousands will try to break into the strip to- day"-a dramatic report on a big march of settlers which might cause confrontation with the security forces, and "toward a resolution”, on the potential confrontation between those opposed disengagement and the military.

When the opponents to disengagement decided not to confront the army, cynical articles presented the evacuees' demonstration as a festival: "the disengagement festival", "returning home", "guarding and weeping", "one day after the protest rally: 100 applications for compensation", and "a month before the pullout: the containers have already arrived to Gush Katif”. However, despite the protest failure, the paper continued to write about the army's preparation for the evacuation: "55,000 soldiers will take part in the evacuation", "the biggest operation of all", and "reserve mobilization for the disengagement has begun". Other reports described the drawer plans of the security forces in case of violent opposition: "the secret exercise of the settlers" - on the fear of the security forces from violent protest demonstrations", and "the refusniks prison"-on the preparations for soldiers refusing to carry out the evacuation.

During August - the month of the actual evacuation-the coverage was factual, and referred to the process as a done deal. The reports contemplated on the evacuation outcome and the political and social implications of the disengagement operation. The political implications dealt with a secret negotiation between Sharon and right wing rabbis, the compromise achieved between the leaders of the evacuees and the army about a protest demonstration of two and one half hours outside Gush Katif borders, the preparation of the Palestinians following the pullout, the pursuit of infiltrators, the final cabinet approval of the evacuation, the resignation of the Finance Minister in protest of the disengagement, the decision to detain several extreme opponents before the pullout, and the army plans of the implementation process to dismantling the settlements.

The coverage had magnified as the scheduled date for the operation drew nearer and had peaked when large crowds of infiltrators tried to enter Gush Katif to resist the evacuation. The headlines were unequivocal on what is going to happen: "it feels like war", "battle on the roof", "a war is awaiting us in northern Samaria”, "24 hours to evacuation of Sa-Nur and Homesh: confrontation has begun-on the verge of explosion", "Minister of Defense and head of General Security Services (GSS) warn: evacuation of north Samaria will be more violent than in Kfar Darom; The danger-use of live ammunition”, "today: fear of serious violence during evacuation of Sa-Nur and Homesh; IDF chief of Staff: we will immediately neutralize any shooter", and "we are ready for the worst".

A week before the evacuation the headlines were unequivocal and succinctly outlining the process: "leave your homes by midnight on Sunday"- - on official letters sent by the army to the residents, six days before the evacuation, demanding voluntary evacuation, "the big desertion"-on residents who decided to leave voluntarily and held farewell ceremonies from the settlements, "preparing for a siege" - on residents who decided not to leave, "the protest" and "the last power demonstration”- on 70,000 people gathering at the Kotel (Western Wall) square to protest against the evacuation, "Sharon: I will not ask for forgiveness from the settlers"-a set alone front-page headline with no article printed four days before the evacuation, "closing down the southern roads", "goodbye Gush Katif", "disengagement 2005- the biggest operation in the history of the state is on the way", "tonight it begins", and "the gate is closing-the evacuation is starting”. 
The coverage during and after the six days of the disengagement operation presented the state of Israel as demonstrating uncompromising might. It was an overwhelming historical and national victory, featured in the paper as pivotal to the country's future. The disengagement plan was fully accomplished, with almost no casualties and in less time than planned by the army or projected by the media. The paper praised the army for well organized preparation and perfect implementation achieved fast and efficiently, with sensitivity to the settlers, executed smoothly and with hardly any casualties. The soldiers were portrayed as heroes, confronted with heart breaking sights yet acting with determination and sensitivity throughout the operation in the searing heat of August. The paper referred also to the global impact of the evacuation, which was extensively covered around the world, featuring the soldiers' patience and professional conduct throughout the operation while being transmitted live on TV channels in Israel and covered extensively worldwide.

The attitude toward the evacuees was bipolar. On one hand, fear from violent collision with the security forces during the evacuation, on the other hand, feelings for people forced to leave their homes. Toward the completion of the operation, when it became clear that there would be no violence during the evacuation, many articles were published recounting personal stories about the pain and emotional hardship experienced by those involved in the event along with pictures of praying and weeping evacuees. Headlines were emotional and succinct, a few words spread saliently on the front page: "final embrace", against the backdrop of a photo of a weeping settler, "the blood will remain here forever" - on families who had lost their loved ones in terrorist acts in Gush Katif and now are forced to leave their homes, and "halleluiah to the synagogue"—on evacuating a synagogue where soldiers were praying and sobbing with the evacuees-yet accomplishing their mission.

\section{The Role of the Press}

The policy of the Israeli security system was traditionally based on the need to prevent advertisement of information on the army and sensitive issues. The perspective of security stems from a situation of prolonged war between Israel and Arab states and armed fanatic organizations, and the daily exposure to terrorist attacks against civilians. For years a wide national consent was created, beyond ideological and political stands, for the need to prevent advertisement that could endanger the national security. This stand was accepted by the public and by the media for many years, since the army and the security system were a principle factor in the gathering of information on security subjects and as such controlled vital information.

The Israeli society has traditionally seen national security as more important that the need of the public to be exposed to sensitive information. The relationship between the media and the government have established the notion that Israel's security issues stand at the heart of its very existence and the common interests of the army and social issues are considered as an issue of national security.

The communication policy throughout the disengagement allowing almost complete freedom of coverage along with extensive and active facilitation by the IDF spokesperson unit for the domestic and foreign media is rather exceptional for closed organizations such as the IDF and the police, whose major part of their daily activities is built on discreetness and closeness to the media. The adoption of global media characteristics caused a re-examination of the Israeli society's approach to covering security topics. Due to the global media contribution which brings available information in real time through the internet, satellite transmissions and cellular communication, changes had occurred in the ability and legitimation of the military censure to sweepingly and without appropriate explanation ban security sensitive information from the Israeli public and the world (Wallsfeld, 2005).

The local and global tendencies that brought about the changes in the media coverage on security issues resulted in the fact that the past army's exclusive authority to ban publicizing information on security issues was not anymore applicable to the disengagement, and it was impossible to fully control the correspondents who are familiar with the grounds and the factors involved in the process-the evacuating forces and the evacuees residents. However, the role of the media remanied supportive of the army and the government and provided little or no coverage to other aspects of the process. Although the army realized that there is no way to stop the correspondents and thus decided to open the operation to media coverage almost with no restrictions, it was the press that restricted its coverage to protect operational needs (Balint, 2005).

Comparison between the army preparations for violent evacuation with many casualties and the final result of violent-free evacuation, points to the huge gap between the basic assumptions of the operation and the actual outcome. Also, the gap between the heavy army forces and the number of soldiers needed for the implementation of the disengagement, and the fact that the evacuation itself was carried out by non-combatant and female soldiers as opposed to the numerous publications about the need for large combatant forces to carry out the implementtation-point to the major role of the media in the operation success (Kaneti, 2005). Throughout the months preceding the disengagement implementation, the army media policy was to prepare the public opinion in Israel and abroad and to properly confront the residents slated for evacuation, and indeed it was a central factor in implementing the goals (Benzimen, 2005).

Analyzing the reports publicized in the main daily newspaper of Israel-Yediot Achronot-from August 1, 2005 through August 24, 2005, with the completion of the evacuation of Israeli citizens, reveal that the newspaper presented a one-sided picture magnifying the image of the Israeli settlers as a violent and dangerous group, and emphasized their plan to forcibly resist the evacuation and threaten the army's ability to enact on the government decision. The newspaper covered the process extensively while consistently avoiding criticizing the disengagement plan. It chose to convey the disengagement as an internal Israeli story, a human tragedy that touches the Israeli society alone-a traumatic event that emphasizes the suffering of all those involved, namely, the settlers, the evacuating soldiers and policemen, as well as the right-wing camp whose ideology of greater Israel is being shattered.

The paper's reporters ignored the political and security implications of the process. The newspaper ignored the implications of the operation on the Israeli-Arab conflict and referred to the entire process as it was planned to be- - a unilateral disengagement, unrelated to the Palestinian side. The paper's coverage also ignored the security arrangements of the Palestinian Authority and the question of what would happen in the Authority after the withdrawal. The paper supported the disengagement decision entirely and did not try to analyze its prob- 
lematic aspects or examine whether the decision to disengage was right. The media adopted the government's position that there was no partner on the other side, thus the disengagement is an internal Israeli affair to be completed in any case, also without the Palestinians' help. Accordingly, substantial issues of political and security implications were not discussed in the press coverage.

Throughout this period the newspaper expressed full support and sympathy to the Prime Minister. Ariel Sharon was portrayed as tenacious, confident in himself and in the decision that he had made regarding the disengagement, acting for the future of the state of Israel, unaffected by the opposition to the process, not hesitant with respect to the disengagement conesquences and appreciative of the good of the country in the long run-especially from the security and demographic aspect. He was portrayed as a strong political leader who knows how to overcome his opponents, recognizes the weak points of each one of them, takes into account all the options of upsetting his moves and constantly thinking about alternatives.

The press coverage portrayed Sharon as a leader who sticks to the goal, yet sensitive and gentle; a person who makes sure that the evacuation will be carried out professionally and with full consideration to the evacuees. Sharon had shown great patience with the evacuees and stressed the importance of keeping their routine intact until evacuation day. He allowed them to have decent farewell ceremonies from their homes and their settlements. Yet, at the same time he did not deviate from the decision he had made which was adopted by the government.

Sharon was portrayed as a determined and resolute leader yet, sensitive, a person who could shed a tear and sympathize with the hardship imposed on the settlers-a person who knows how to separate national responsibility from personal feelings. The newspaper also emphasized his personal story; the man who was responsible for building the settlement is now responsible for their dismantling. To support its position the paper publiccized a survey results that showed an impressive public support in Sharon: $61 \%$ believed that he is the right person to lead Israel and $50 \%$ thought that no other leader is capable to implementing the disengagement.

Also when dealing with the settlers, Sharon was portrayed in a positive light. Following his agreement with the settlers on an organized transfer to Nitzanim area, he was portrayed as a practical, considerate and sensitive man. He was depicted as polite, listens to his opponents and talks with them eye to eye with consideration to their predicaments. The media sympathized with Sharon's claims that the disengagement is inevitable under the circumstances, and his attentiveness to the evacuees points to his qualities as a leader. The media stressed Sharon's attitude toward the operation while ordering the army to proceed"bring in the bulldozers, start leveling the grounds, start working".

For all Sharon's determination, the paper still supported his decision to postpone the evacuation. Sharon consented to the demand to delay the operation by three weeks for religious reasons (the period of Bein HaMetzarim, during which it is forbidden to relocate according to the Halacha), and was portrayed by the paper in a positive light, as a man open to suggestions from his cabinet members and not rushing to make a decision that might hurt the unity of the people. The newspaper came with another reason for the disengagement's delay, namely the fact that the area designated to absorb the evacuees had not yet been ready.

It is evident from this study that the press coverage created an organized script in three stages: first, the settlers were portrayed as fanatic and violent, then, articles were published about the determined position of the government, and finally, the actions to be carried out by the army against the violent forces were displayed. The coverage portrayed the settlers as the negative element in the process, while the army was the positive element. After creating such image, the newspaper relayed the steps that the good element would take in order to prevent the bad element from impeding the implementation of the government's decision.

\section{REFERENCES}

Arlich, A. (1993). Society in war: The national conflict and the social build. In U. Ram (Ed.), The Israeli society_Criticism aspects. Beirut: Beirut Publications.

Balint, A. (2005). IDF spokesperson: The IDF hasn't had press like that since 1967. Ha'aretz.

Beckerman, G. (2005). Disengaged. Columbia Journalism Review, 44, 40-50.

Benzimen, U. (2005) In the eyes of the beholder. The Seventh Eye, 58.

Eisenberg, Z. L., Caplan, N., Sokoloff, B. N., \& Abu-Nimer, M. (Eds.) (2003). Traditions and transitions in Israel. New York: State University of New York Press.

Gilboa \& Katz (2001). The media in the 1999 Israeli elections. Israel Affairs, 7, 223-244.

Goldscherder, C. (2002). Israel's changing society. New York: Westview.

Kaneti, N. (2005) Warriors' brotherhood. The Seventh Eye, 58.

Katz, Y. (1999). Local culture and multi-channel-Can the two go together? Tel Aviv: Tel Aviv University.

Kimberling, B. (2003). The Israeli state and society. New York: State University of New York Press.

Levi-Paur, D., Sheffer, G., \& Vogal, D. (Eds.) (1999). Israel: The dynamics of change and continuity. London: Frank Cass.

Maoz, I. (2006). The effect of news coverage concerning the opponents: Reaction to a concession on its evaluation in the Israeli-Palestinian conflict. The Harvard International Journal of Press/Politics, 11, 70. doi:10.1177/1081180X06293548

Melman, Y. (1993). The new Israelis. Tel Aviv: Shoken Publications.

Negbi, M. (1995). Freedom of press in Israel: Values in the legal mirror. Jerusalem: Jerusalem Institute for the Research of Israel.

Shafir, G., \& Yoav, P. (2002). Being Israeli. Cambridge: Cambridge University Press.

Strashnov, A. (1994). Justice under fire-The legal system in the intifada. Tel Aviv: Yedioth Aharonot Publications.

Sucharov, M. (2005). Security ethics and the modern military: The case of Israel defense forces. Armed Forces \& Society, 31, 169-199. doi:10.1177/0095327X0503100202

Tenenboim-Weinblatt, K. (2008). We will get through this together: Journalism, trauma and the Israeli disengagement from the Gaza Strip. Media Culture Society, 30, 495. doi:10.1177/0163443708091179

Wallsfeld, G. (2005) The cameras restrained the conflict. The Seventh Eye, 59. 